\title{
LANGUAGE CONTACT: A BLIND SPOT IN 'THINGS LINGUISTIC'
}

\author{
Robert Nicolaï
}

\author{
Institut Universitaire de France \& Université de Nice
}

There come times when the place of fact in a descriptive configuration changes, when new topics become relevant, when all phenomena can no longer be easily accounted for, when explanatory principles lose their absolute validity. A change of perspective upsets the descriptive framework and diverts attention to new problems which presage conceptual renewal and theoretical reconstruction founded on a changed understanding of the reality to be described. The subject of language contact is currently undergoing a process of this kind. The subject is not new ${ }^{6}$, but its place in the domain of linguistic research has changed: the study of contact-induced change of whatever kind is no longer of secondary importance. It has moved from side to center stage.

Why has this subject been minimized till now? Could it be simply that the notion of "contact" suggests a particular category of metaphors and entails preconceived kinds of ideas, phenomena, and objects: ones which can "come into contact" with one another? And that this presupposes the existence of prime entities which chance and contingency cause to "collide", which undergo the consequences of this collision, apparently withstanding it fairly well and retaining more or less their original forms and features? Clearly, immersed in such a system of predictive and retrodictive inferences, we find ourselves caught up by a common-sense logic and an argumentation which constantly feeds on both our ideological and philosophical constructs (such as the nature of language) and our theoretical and empirical constructs (such as the structure and features of language) within an apodictic mirage.

\footnotetext{
${ }^{6}$ The first appearance of the subject in contemporary linguistic literature is generally attributed to Weinreich (1953). Likewise, interest in the role of language contact is assumed to have originated in connection with the wider question of language change.
} 


\section{Starting over}

Under the weight of these prior certainties, we in the field of contact have developed two descriptive strategies, which fit well into what I call damage limitation.

- The first of these consists of treating the problem as marginal to the field of research: contact factors are treated as epiphenomena and minimized in the ordinary theories and models which regard a "language" as a unitary entity. Contact is therefore apprehended, not as an integral part of a complex, but as an unnecessary contingent complication of a simple situation which is assumed to be normal and basic. Contact data cannot then be dealt with as a manifestation of a primary complex phenomenon demanding an analysis which can put the researcher's theoretical approaches and analytical frameworks to a test.

- The second consists of fencing the problem off: a field of study is defined with a range of topics (rather than as a source of topics) associated with a given context, and a scientific approach is developed to deal with them which, if not ad hoc, is at least specific to the field in a way that sets it off from neighboring ones. Its subject matter takes on a definable essence and is provided with an "ontology": "creole studies" are an example of this procedure.

Naturally, either of these approaches will suffice to account for many things: the general theory of language is enhanced and the stock of available knowledge is enriched, since empirical studies are often accompanied by theorization whereby "concepts" arise from contextualized descriptions (e.g., "pidgin", "pidginization", "pidginization process", etc.). Yet if a name were required for procedures of this kind, I would tend to call them "patch-ups". By this I mean the continual one-off modification of a given theoretical framework to account for every new fact observed in the field with little regard for their ultimate significance and no awareness of whether these changes might not be masking important functional features of language with consequences for our overall understanding. The time must therefore come when the choice is made to reject both damage limitation and patch-ups and make a new start.

The creation of the Journal of Language Contact, particularly this first issue which is also the first in the THEMA series, is a response to these observations: it is intended to help fill a gap. The exploration of new empirical fields, epistemological insights, and a search for adequate models have renovated our understanding of language contact in tandem with reconceptualizations in the theoretical domain, and this is why there is a sharply felt need for a new communicative tool as a support for scientific advances.

Major changes have affected all fields of research. Many formerly unassailable principles are now seen as debatable, thus relativizing rules and norms which were formerly considered selfevident. A vague overgeneralization? Then let us be more specific.

We started from a situation where:

- all analysis was grounded on a preconception of language as a coherent, homogeneous, and systemically stable entity.

- The normal mode of language change was represented as process of incessant splitting driven by factors over which speakers have no control.

- Only those features of language which revealed (or confirmed) its unitary nature underlying any formal variation were judged worthy of study.

- $\quad$ Reductive mechanisms and conceptual limitations cutting the objects of study off from contextual references predominated.

Today we have a new situation where: 
- both formal heterogeneity and systemic plurality are accepted as normal and incorporated into the description of factually observed language processes.

- A distinction between "internal" and "external" factors in change is no longer an essential feature of any "good" explanation.

- It is commonly accepted that variation is not something to be swept aside and disposed of, but rather a reality requiring analysis and explanation if the language function is to be properly understood.

- It is becoming clear that accounting for linguistic processes by relying on abstraction from systemic constructs alone is impossible, and that we need the full range of intersecting and interplaying approaches, unconstrained by structural determinism.

- A language cannot be not rooted in an abstract universe but only in the materiality of interpersonal and intergroup relations through the action of the historical consciousness we produce as we live out our lives.

These two mentalities clash, yet a pendular movement does not signify the replacement of earlier theoretical and methodological positions by their antitheses. It is rather a matter of broadening our view and refocusing our research.

Clearly, once the existence of contact and the patent necessity of allowing for heterogeneity is recognized, there will still be a need for representations of homogeneity, identity, and formal stability. Students of language will always want to set up systems. But system building can become richer than ever before if it will allow for intersecting and interacting approaches, for shifting contextualization and categorization of communicative phenomena and events, and seek to decode the real observed complexities of language behavior. This richness will surpass the structurally closed universe where systemic and cognitive representations involve cut-offs and vanishing points, by emerging from a struggle to understand how heterogeneity can be constituent to homogeneity. The complex relationship between homogeneous constructs and factual heterogeneity must now be subjected to scrutiny. This study is essential to take us beyond the elementary stage of peremptory and naively postulated a priori affirmations regarding the nature of phenomena and their representations.

We are not (and doubtless never have been) in the simplistic situation of attaining to / constructing / (re)discovering "the truth". Truth as such is irrelevant and lies outside our domain. It belongs rather to the spheres of religion and dogma or to the fields of logic and mathematics (though these be different kinds of truth). On our empirical level, we need not take positions involving any kind of truth.

\section{JLC's outlook}

Where to begin, then? How to launch this first issue entitled Contact: Framing its Theories and Descriptions / Contact : descriptions, théorisations, cadrages? There is probably no perfect way to go about it as the field is too vast, the issues too diverse, the subjects too complex. That is why we have simply asked some of the scholars engaged in the study of language contact and the rethinking of the concepts emerging from the development of the field to examine whichever aspect they had made their current center of attention. It is to be hoped that the resulting interplay of themes will enable us to define, not so much a set of guidelines as a stage where a large part of the current renewal is taking shape. It should then be possible to get back to our bases with a new view of the horizons for our research.

The scholars who have agreed to participate in this issue are not necessarily all in agreement. In addition, nowhere near all the schools of thought and centers of interest in the field of language contact are represented here. Nevertheless, all these authors have left their mark in the field through their publications, their thematic interests, and their theoretical outlooks. I will not try to summarize 
each individual contribution, but I will mention a few of the main points they make and discuss a few aspects of the issues they raise, whether singly or repeatedly, in order to give an idea of the breadth of coverage. Let us then begin.

D. Winford's critical study of work in the field of language contact (Some issues in the study of language contact) points out the imprecisions in the way the phenomena traditionally covered by the notions of convergence and borrowing are defined, and suggests ways of developing an "integrated" theory of contact-induced language change. This requires taking account of psycholinguistic aspects of communication. He proposes a model for the mechanisms of transmission of language change, not just for the sociolinguistic mechanisms of the diffusion of change. His sources are Van Coetsem (1988, 2000), whose ideas he has helped to make more widely known, and the latest models formulated by Carol Myers-Scotton and Janice Jake (2000, 2001, 2003). This approach is interesting in its generality and scope, in its attempt to go beyond mere anthroposocial observations and raw linguistic data to build a general model capable of theorizing contact-induced language change in terms of the behavior of the participants in the process in different roles as vectors of change. This yields both a broadening of our horizon and a synthetic program.

In her paper (Language contact and deliberate change), Sarah Thomason takes up what seems to be a problem of detail, though this is only an appearance masking a fundamental issue. She asks: To what extent can speakers make choices and consciously manipulate their language? To what extent can these actions (assuming they exist) modify the form if not the content of their language? She presents a number of examples showing that this can indeed be done: speakers as participants in communicative exchanges actually have the ability to modify the form of the codes they use and reorganize their linguistic systems. Under extreme conditions, such activity can bring about drastic linguistic change, plausibly exemplified by Ma'a and the Lengua Media. But this poses an obvious problem which Thomason states as follows: Why is it that the Comparative Method works so well, if speakers can and do decide (at least in some cases) what changes to make in their language?

The answer is that "having an ability" does not necessarily mean that this ability will be used to its limit. Though control over language manifests itself in ordinary language processes, and such basic realities as generational differences, language play, and processes of social organization testify to its existence, the fact is that it only gives rise to permanent effects in the rarest of cases. This is why the comparative method works so well despite the ability of individuals and societies to make conscious changes.

In Population movements and contacts in language evolution, Salikoko Mufwene brings together three important points for the general theory of language change which he has developed in earlier publications. The first is the criticism of those positions which attribute linguistic specificity to creole languages, i.e., which assume that they develop structural features distinguishing them from "normal" languages. He forcefully shows that creole languages are in no way different from noncreole languages and that furthermore some European languages (including English) show a history of change which is similar to that which creole languages have undergone. He holds that creole languages are ultimately nothing more and nothing less than the final stage of development of the Indo-European languages after several thousand years of migration across the world. His second point has the status of a presupposition. It involves what he has elsewhere $(2001,2005)$ referred to as language ecology: so-called creole languages undergo processes of change deriving from the specific ecological conditions under which they arise. Furthermore, if the term "creole" can have any meaning, it is not in the domain of linguistics but in the fields of history and anthropology. The third point is merely implicit and involves the ideological background against which we for the most 
part unconsciously project our scientific representations of phenomena. I will go no further into this aspect since Mufwene himself has not done so, but it appears clearly in his particular concern with the denotations and categorizations implied by the very mention of creole languages.

Drawing on earlier work between 1984 and 2000 at the Universities of Bâle, Lausanne, and Neuchâtel (Lüdi, Py et al. 1995, Lüdi and Py 2003, Py et al. 2000), Bernard Py (Apprendre une langue et devenir bilingue : un éclairage acquisitionniste sur les contacts des langues) suggests that we set aside questions of mixed languages and creoles and direct our attention to another area of language contact: the apparently well referenced field of language learning and bilingualism. But he is concerned with more than the language learning and bilingualism of pedagogical manuals. He takes us through a synthesis of language acquisition theory at grips with the reality of bilingualism and language contact in the framework of formal and informal learning situations. Ultimately, he poses the fundamental question: How does an individual in a specific sociocultural role become bilingual when he is immersed in a given alloglottal or diglossal community practicing bilingual or exolingual communication? He replies with an elegant critique of, and improvement on, the abstract notions of "exposure to a target language" and "system" by allowing for the circumstances and contextualization of acquisition. He stresses the relevance of asymmetry in exolingual communication and insightfully reflects on the process by which the learner decontextualizes the linguistic data to which he is exposed in order to build up a set of stable resources which can be put to whatever use may be required of them according to context. This leads him to question the usefulness of the notion of competence so that bilingualism can be redefined in terms of access to resources (provided by two different languages) which can be brought into play in specific social contexts (cf. R. Porquier 1984, 1995; C. Perdue 1993; J. Arditty and M.-Th. Vasseur 2002).

Under the title Why languages and contacts?, Petr Zima focuses on the distinction between the domain of linguistic interference and that of social contact among individuals who use their available codes in well defined situations of exchange. He insists strongly on the need to separate the former, assigned to linguistics, from the latter, which must be understood in terms of the anthropology of communication, thus showing the multidisciplinary nature of the study of language contact. At the same time, he sets out a typology of models for communicational contact classified according to criteria such as intensity, quantity, and quality. Allowance can then be made for the stratification found in both the anthropological setting in which communication takes place and in the language situation. Finally, he attributes the observed complexity of contact structures to interplay in this dual stratification.

In 1996, Malcom Ross laid out the notion of metatypy which has since proven so fruitful. Now, in Calquing and metatypy, he deconstructs his earlier account of metatypy and asserts that it is preceded chronologically by lexical and grammatical "calquing", a separate process rather than an early stage of a single general process. He qualitatively distinguises calquing processes, which are nvertheless preconditions for the morphosyntactic restructuring which constitutes metatypy. His reason for making this distinction is that there are languages where lexical and grammatical calques are found with little or no syntactic restructuring. Rather than placing these languages on a scale of metatypy, he prefers to treat them as having undergone calquing without metatypy. This solution allows him to approach the question of how metatypy develops as a function of the degree of structural difference between the languages in contact. Metatypy thereby becomes a specific type of contact-induced change together with language shift, pidginization, and language mixing. Ross then postulates the strong hypothesis that "by default, contact-induced morphosyntactic change in one of a bilingual community's languages entails the restructuring of the whole grammar on the model of 
the community's other language. That is, metatypy is the default, and the borrowing of single constructions a rarity that requires special explanation". All of this involves the correlative theoretical elaboration that lexical and grammatical calquing, like metatypy, arises from the bilingual speakers' need to express the same ideas in both their languages. The (semantic) organization of the lexicon and the morphological paradigms, structure and meaning of lexicalized phrases, syntax, and grammatical functions are all affected by this osmosis because they all encode meaning. Finally, drawing on an approach attributed to Grace $(1981,1987)$, despite similarities with Hjelmslev's (1961) view of isomorphism and levels of language structure, he envisages the existence of a number of different "content substances" expressing the "same" notion.

From the standpoint of contact, addressing the longstanding tension between genetic and areal explanations for similarities among languages, Marianne Mithun (Grammar, Contact and Time) shows that certain grammatical traits which might at first be assumed to be 'unborrowable', and thus indicators of genetic relations, may not be what they seem. The point is illustrated with recurring parallelisms in morphological structure found in languages indigenous to western North America. The area is home to tremendous genetic diversity, with not only numerous languages but also numerous genetic families in the traditional sense. Many of the languages exhibit elaborate sets of verbal prefixes indicating means and manner of action. Many contain rich sets of verbal suffixes indicating location and direction. Structures like these have sometimes been offered as evidence of superstocks, groups of families related at a more ancient time depth than that recoverable by the traditional comparative method. Here it is shown that such parallel linguistic patterns need not be the result of either shared history or borrowing as such. Rather, it may have been the precursors to the structures that were transferred, sometimes simply as propensities for certain expressive or stylistic choices that subsequently crystallized in the various languages in parallel ways.

In this volume, code-switching (CS) itself is not a theme, though this is one of the most "popular" topics in the study of language contact, having been examined from the most varied viewpoints: linguistic, sociolinguistic, and psycholinguistic. In Le code-switching comme ressource pour l'organisation de la parole-en-interaction, Lorenza Mondada targets something far more specific: the contribution of interactional linguistics to the analysis of CS insofar as it can be considered as a contingent locally available interactional resource available to speakers in response to the sequential organization of ongoing interaction. This aspect, which might seem a priori to be marginal here, is in fact nothing less than fundamental, as she shows in her discussion of a representative sequence and the exchanges which take place as it unfolds. CS is thus apprehended as a laboratory for linguistics. She seeks explanations for its pragmatic and sociolinguistic functions, reviews the ways in which its polyfunctionality can be conceptualized, and globally rethinks the question of interactive language by showing how it can itself be a tool for organizing the interaction.

The short example of professional interaction which she provides against the background of Auer's (1984) perspectives on the contextualization of CS and Sacks's $(1972,1992)$ work on categorial apparatus and conversational analysis enable her to open new horizons.

Finally, Robert Nicolaï (Contacts des langues et contact dans la langue : hétérogénéité, construction de l'homogène et émergence du 'linguistique') returns to the subject of contact by arguing that the reality of contact is essential to a general understanding of how language works and of what he calls "things linguistic" (see below, §4). As has already been made clear, the primary practical focus should thus be not on linguistic structure, which is a construct, but rather on exchange and contact between languages and language varieties within social fabrics through the interplay of the available repertories. Elaborating on the theme of heterogeneity in communication, 
he devotes his attention to linguistic variation and the construction of supposedly homogeneous entities, discusses the position assigned to discourse constraints, and further develops his notion of 'fine layering' (2001, 2003a, 2005). He goes on to examine processes of semiotization as essential features of linguistic and communicational innovation or restructuring, and then uses the notion of contact as constitutive of what he calls "things linguistic" and makes it the condition of all innovative processes in meaning.

\section{Backdrops}

These varied approaches all illustrate advances in the study of contact, even though, as already stated, they do not cover the entire field. At the same time, they are grounded in reflection on how language works, how languages develop, how language processes can be recognized and described. I would like to close this introduction by returning to two recurrent themes referred to above which seem to me to be particularly important in view of their generality and their implications.

1. The range of the field of study and the intersection of approaches (cognition, social anthropology, linguistics, etc.)

It is interesting to note that all the texts in this volume, faced with issues of language contact and hence with setting "boundaries", presuppose having defined or revised boundaries on quite another level, sc., between scientific disciplines. This, however, is as far as the general agreement goes. Recognizing an intersection of explanatory approaches with respect to some specific object of study does not imply a need to make identical theoretical choices as a result. Participation in a common endeavor does not mean sharing a single manner of approach. While a continuity of integration of linguistic, sociolinguistic, anthropological, and cognitive approaches is apparent from Winford's synthetic proposals to Ross's or Mithun's developments, there is no guarantee that this will lead to the adoption of a common analytical framework. And even within such a framework, there is a range of issues to be dealt with.

To see how wide the divergence can be, we need only compare, for example, Zima's strategy of decontextualization and classification for the purpose setting up the degrees and categorial constructs of his anthropological setting, and Mondada's interactional approach stressing contextualisation and sequentiality and showing how seemingly adequate functional categories are elaborated and continually worked over in context, thus preventing them from serving as reference points.

In other words, recognizing that there is work to be done along the borderline of disciplinary fields, hence recognizing the existing border and its relevance, does not entail that the way in which that border is taken into account is predetermined, nor that it need be made an issue in the same way.

At the same time, the standard "academic" problem of the use of reductive processes for scientific ends (another attempt at drawing borders) comes to the fore: What justification is there for basing the construction of an object of study on the closure of a domain and the choice of a set of relevant axes to govern its organization?

2. Essentialist and symbolic representations vs. contextually generated processes of continual reorganization and adaptation

This theme, too, more or less directly underlies several papers and has as a backdrop an unstated problem which seems crucial to me: the construction of the homogeneous from the reality of the heterogeneous.

This theme requires distinguishing two levels. 
- $\quad$ On the first level are objectivized propositions and utterances. Here is where knowledge is built up from observing "ordinary" participants in their exchanges, the processes of transformation and reworking of material linguistic elements which are both the vectors and the results of those processes.

- $\quad$ On the second level are the implicit elements and inferences from propositions. Here is where we find the selections and outputs of "informed" participants who provide a supposedly "objective" account of given aspects of those material features and processes. This is thus the level of those who see themselves as describing reality and producing explicitly decontextualized knowledge ${ }^{7}$.

On the first level where the behavior of "ordinary" participants is apprehended, it is easy to see the value, the necessity even, of taking into consideration their "ideas about their language" and the symbolic representations which they produce, argue over, cling to, or relinquish in the course of communication. Despite patent differences in their aims, theoretical references, and descriptive projects, approaches as different as those of Py, Thomason, and Mondada show a "first-level" interest in the production of linguistic forms from a preexisting multiplicity of languages and linguistic behavior patterns which the participants in communication already possess or acquire in context. Obviously, the practical processes of construction and symbolization exercised by the language learner are of a different order from the ones used by the participants in code-switching as described by Mondada. A fortiori, these are even further removed from the processes by which speakers develop linguistic differentiations to mark their identity, which are Thomason's subject. Nonetheless, in each case, there is a contextually developed process of rearrangement and adaptation which leads to the perception of categorized entities whose "essence" is (re)defined. These are essentialized representations whose symbolic value can be activated as a function of individual or collective contextual strategies. Once activated, they take on historical sense and become a pratical tool of strategic negotiation in the pursuit of interaction.

There is, however, generally less interest in what happens on the second level, i.e., in the behavior and practices of the describer. He is rarely questioned regarding the implicit aspects of his output, the nature of his theoretical assumptions, and the implications of his models ${ }^{8}$. By "describer", I mean the person who gives an account of something, who plays a role requiring reflection and symbolizes his objectivity by placing himself a priori outside the scope of the phenomena he seeks to apprehend ${ }^{9}$. Actually, given that utterances on the second level necessarily state implicit features, they can only be criticized through reference to the explicit propositions observed on the first level. Thus, when Mufwene criticizes some of the explanatory hypotheses which have been put forth concerning the origin, development, and specificity of creole languages, he calls for first-level reflections on the phenomena generated by ordinary participants in communication; but these must necessarily be accompanied by reflections on the implicit propositions and presuppositions of informed participants in description, which eminently pertain to the set of things which I have assigned to the second level. Indeed, could anything at all be described without implicit assumptions and presuppositions?

\footnotetext{
${ }^{7}$ Even when, paradoxically, the describer proposes to give an account of the indexicality of the actions and representations he examines.

${ }^{8}$ For further reflections on this subject, see Nicolaï (2003b; in press a, b).

${ }^{9}$ As if he were not himself a participant in these phenomena; as if description, "accounting for", occurred outside the contingent world in an ideal space where a reasoned immanence could be worked up and thus postulated as necessarily existing; in a world where he could operate as an ideal link between the world of consumers of knowledge and that of the producers of realia for description.
} 


\section{Constructing 'things linguistic'}

I would like to conclude this introduction with three assertions which I hope can define the most stable elements in the conceptual revisions and rethinking forced upon us by the development of the consideration of language contact and the resulting processes of change.

- It is apparent in many ways that understanding contact-induced language change requires that material linguistic facts be treated not merely as objects of description but as tools which can be used to carry on human communication in the broadest sense sense, and that this communication is in turn elaborated, governed, and shaped by those material facts.

- $\quad$ Languages thus root themselves in the material forms of contact between individuals and groups and in the historical consciousness which arises in the course of our existence. It is impossible to account for language processes without taking into consideration all the intersections and realignments of approach which occur in what I have finally decided to refer to by the expression 'things linguistic'.

- As an object of study, 'things linguistic' are characterized by heterogeneity of form, variability, and multiplicity of systems and languages. Variation in all its forms is the reality to be analyzed and understood in order to grasp the way in which 'things linguistic' work.

These three assertions are, of course, no more than an attempt to contribute to an open debate. Conceiving our approaches as operating in the realm of 'things linguistic" ${ }^{10}$ is merely a way of reaffirming the evident link between our object of study and the linguistic facts and behaviors of the real world, while preserving it from the a priori closure that the use of the terminology of a single discipline (linguistics) would tend to impose on it. Indeed, "one does linguistics" by practicing a scientific discipline where a preexisting theoretical framework defines the relevant topics and preconstrains the objects of study and how they are described. "One deals with things linguistic", however, by seeking to define an object and seeking a way to describe and analyze it, by finding a way of capturing reality in relationship to its relevant features. This means theorizing practice and defining a field of research.

\section{References}

Arditty, Jo \& Vasseur, Marie-Thérèse. 2002. Contextes, variabilité et activités d'appropriation des langues. Discours, action et appropriation des langues éd. par Francine Cicurel \& Daniel Véronique, 251-264. Paris : Presses de la Sorbonne-Nouvelle.

Auer, Peter. 1984. Bilingual conversation. Amsterdam: John Benjamins.

Gadet, Françoise. 2004. La signification sociale de la variation, Romanistisches Jahrbuch 54 : 98 114.

\footnotetext{
${ }^{10}$ This usage of 'things linguistic' is doubtless in debt to Fr. Gadet (2004) who distinguishes sociolinguistics (la sociolinguistique) from what she calls "things sociolinguistic" ("le sociolinguistique").
} 
Grace, George W. 1981. An essay on language. Columbia, SC: Hornbeam.

Grace, George W. 1987. The linguistic construction of reality. London: Croom Helm.

Hjelmslev, Louis. 1961. Prologomena to a theory of language. $2^{\text {nd }}$ ed. Madison: University of Wisconsin Press.

Lüdi, Georges, Bernard Py \& al. 1995. Changement de langage et langage du changement. Aspects linguistiques de la migration interne en Suisse. Lausanne : l'Age d'homme.

Lüdi, Georges \& Bernard Py. 2003 [1986]. Etre bilingue. Berne : Lang, $3^{\text {ème }}$ édition revue.

Mufwene, Salikoko S. 2001. The ecology of language evolution. Cambridge: Cambridge University Press.

Mufwene, Salikoko S. 2005. Créoles, écologie sociale, évolution linguistique. Paris: L’Harmattan.

Myers-Scotton, Carol. 2003. "What lies beneath: Split (mixed) languages as contact phenomena." The Mixed Language Debate: Theoretical and empirical advances ed. by Yaron Matras \& Peter Bakker, 73-106. Berlin \& New York: Mouton de Gruyter.

Myers-Scotton, Carol \& Janice Jake (eds.). 2000. Testing a model of morpheme classification with language contact data. International Journal of Bilingualism 4/1. (Special Issue).

Myers-Scotton, Carol \& Janice Jake. 2001. Explaining aspects of codeswitching and their implications. One mind, two languages: Bilingual Language Processing ed. by Janet Nicol, 84-116. Oxford: Blackwell.

Nicolaï, Robert. 2001. La “ construction de l'unitaire " et le " sentiment de l'unité " dans la saisie du contact des langues, Langues en contact et incidences subjectives. Traverses 2. 359-85, Montpellier.

Nicolaï, Robert. 2003a. Contact et genèse : ouvertures et perspectives : pour un «Nouveau Programme » de recherche sur l'évolution des langues. Proceedings, XVII International Congress of Linguists Prague, July 24-29, 2003, CD-ROM, MATFYZPRESS, vydavatelství matematicko-fyzikální fakulty Univerzity Karlovy v Praze.

Nicolaï, Robert. 2003b. La force des choses ou l'épreuve nilo-saharienne: questions sur les reconstructions archéologiques et l'évolution des langues. Köln : Köppe.

Nicolaï, Robert. 2005. Language processes, theory and description of language change, and building on the past: lessons from Songhay. Linguistic Diversity and Language Theories ed. by Zygmunt Frajzyngier, Adam Hodges \& David S. Rood, 81-104. Amsterdam \& Philadelphia: John Benjamins.

Nicolaï, Robert. sous presse-a. Remarques sur la construction des faits et l'activisme inhérent de nos constructions catégorielles, Essais de Linguistique Générale et de Typologie Linguistique, en Hommage à D. Creissels.

Nicolaï, Robert. sous presse-b. De la généalogie des langues au contact : théorie à la limite à l'épreuve du songhay. Comparative Semito-Hamitic (Afro-Asiatic) Festschrift for A. Dolgopolsky and H. Jungraithmayr ed. by Gabor Takács.

Perdue, Clive (ed.). 1993. Adult second language acquisition : cross-linguistic perspectives. Vol. I : Field methods. Vol. II : The results. Cambridge: Cambridge University Press. 
Porquier, Rémy. 1984. Communication exolingue et apprentissage des langues. Acquisition d'une langue étrangère III. Actes du colloque organisé les 16-18 septembre 1982 à l'Université de Neuchâtel éd. par Bernard Py, 17-47. Paris: Encrages.

Porquier, Rémy. 1995. Trajectoires d'apprentissage(s) de langues : diversité et multiplicité des parcours, Etudes de linguistique appliquée 98 : 92-102.

Py, Bernard \& al. 2000. Analyse conversationnelle et représentations sociales. Unité et diversité de l'image du bilinguisme. Travaux neuchâtelois de linguistique (TRANEL) 32: 39-53.

Ross, Malcolm. 1996. Contact-induced change and the comparative method: cases from Papua New Guinea. The comparative method reviewed: regularity and irregularity in language change ed. by Mark Durie \& Malcolm Ross, 180-217. New York: Oxford University Press.

Sacks, Harvey. 1972. An initial investigation of the usability of conversational materials for doing sociology. Studies in Social Interaction ed. by David Sudnow, 31-74. New York: Free Press.

Sacks, Harvey. 1992. Lectures on Conversation. London: Blackwell, 2 vols.

Van Coetsem, Frans. 1988. Loan phonology and the two transfer types in language contact. Dordrecht: Foris.

Van Coetsem, Frans. 2000. A general and unified theory of the transmission process in language contact. Heidelberg: Universitätsverlag, C. Winter. 